\title{
New Auxiliary Indicators for the Differential Diagnosis of Functional Cardiorespiratory Limitation in Patients with Chronic Obstructive Pulmonary Disease and Congestive Heart Failure
}

\author{
Marcelo de Castro Cesar, Aquiles Camelier, José Roberto Jardim, Fábio Tadeu Montesano, \\ Antonio Sérgio Tebexreni, Turíbio Leite de Barros
}

São Paulo, SP - Brazil

\begin{abstract}
Objective - To differentiate the nature of functional cardiorespiratory limitations during exercise in individuals with chronic obstructive pulmonary disease (COPD) or congestive heart failure (CHF) and to determine indicators that may help their classifications.
\end{abstract}

Methods - The study comprised 40 patients: 23 with COPD and 17 with CHF. All individuals underwent maximal cardiopulmonary exercise testing on a treadmill.

Results - The values of peak gas exchange ratio $(R$ peak), peak carbon dioxide production ( $\mathrm{VCO}_{2}$ peak), and peak oxygen ventilatory equivalent $\left(\mathrm{V}_{E} \mathrm{O}_{2}\right.$ peak) were higher in the patients with CHF than in those with COPD, and, therefore, those were the variables that characterized the differences between the groups. For group classification, the differentiating functions with the $\mathrm{R}$ peak, $\mathrm{VCO}_{2}$ peak (L/min), and $V_{E} \mathrm{O}_{2}$ peak variables were used as follows: group COPD: $-44.886+78.832 x R$ peak $+5.442 x$ $\mathrm{VCO}_{2}$ peak $+0.336 \times \mathrm{V}_{E} \mathrm{O}_{2}$ peak; group $\mathrm{CHF}:-69.251+$ $89.740 x$ Reak $+8.461 \times \mathrm{VCO}_{2}$ peak $+0.574 \times \mathrm{V}_{E} \mathrm{O}_{2}$ peak. The differentiating function, whose result is greater, correctly classifies the patient's group as $90 \%$.

Conclusion - The R peak, $\mathrm{VCO}_{2}$ peak, and $\mathrm{V}_{E} \mathrm{O}_{2}$ peak values may be used to identify the cause of the functional cardiorespiratory limitations in patients with COPD and $\mathrm{CHF}$.

Keywords: exercise, obstructive pulmonary diseases, congestive heart failure

Centro de Medicina da Atividade Física e do Esporte (CEMAFE) e Centro de Reabilitação Pulmonar da UNIFESP/EPM.

Mailing address: Marcelo de Castro Cesar - Faculdade de Ciências da Saúde FACIS - Caixa postal 68 - Rodovia do Açúcar, Km 156 - Taquaral; 13400-911Piracicaba, SP - Brazil - E-maill: maccesar@unimep.br

English version by Stela Maris C. e Gandour
The major function of the cardiovascular and ventilatory systems is gas transportation between the cells and the atmosphere. Deficiencies in the function of these systems are better observed during exercise, because cellular respiration is stimulated and the defects are amplified. Because each component of the gas transportation system binds the external medium to internal respiration with a different function, abnormalities in gas exchanges differ according to the pathophysiology. Recognizing these differences allows the examiner to determine which patient's system is the major cause of exercise limitations ${ }^{1}$.

Nery et $\mathrm{al}^{2}$ compared the respiratory and cardiovascular responses to exercise in patients with chronic obstructive pulmonary disease (COPD), mitral valve disease, and healthy individuals. Maximal oxygen uptake $\left(\mathrm{VO}_{2} \max \right)$ was higher in healthy individuals as compared with that in the patients, and although the latter developed acidosis at the end of the assessment, that was primarily respiratory in patients with COPD and totally metabolic in patients with mitral valve disease. The ratio between pulmonary ventilation and oxygen consumption, the so-called oxygen ventilatory equivalent $\left(\mathrm{V}_{\mathrm{E}} \mathrm{O}_{2}\right)$, was higher in the 2 groups of patients as compared with that in the control group, and the ventilatory reserve was significantly lower in patients with COPD $(13 \%)$ as compared with that in mitral patients (49\%) and the control group (44\%). These findings indicate that patients with mitral valve disease have exercise limitations due to the cardiovascular response of the oxygen transportation system, this being the primary factor of their functional limitation; on the other hand, patients with COPD are impaired by ventilatory limitations.

According to Weber et $\mathrm{al}^{3}$, the cause of dyspnea, whether cardiac or ventilatory, may be determined by cardiopulmonary exercise testing with the following criteria: in patients with heart disease, maximal oxygen uptake and 
anaerobic threshold are reached, but they are below normal, while in patients with ventilatory limitations, they are not reached. The maximal ventilation values during exercise do not exceed $50 \%$ of maximal voluntary ventilation in patients with cardiac limitations and exceed $70 \%$ in patients with ventilatory limitations. Peripheral oxygen saturation does not drop below $90 \%$ in patients with heart disease, and hypoxemia frequently appears in patients with pulmonary disease.

Although no consensus about how to quantify the maximal ventilatory capacity exists, the following indicators suggest the presence of ventilatory limitations during exercise $^{4}$ : maximal ventilation during exercise approaches $100 \%$ of maximal voluntary ventilation or maximal sustained ventilation for 4 minutes; determination of the flow-volume loop during exercise as compared with the flow-volume loop at rest may indicate a limitation in the expiratory flow; the absence of an anaerobic threshold during exercise; and limitation in the increase of the oxygen $\left(\mathrm{V}_{\mathrm{E}} \mathrm{O}_{2}\right)$ and carbon dioxide $\left(\mathrm{V}_{\mathrm{E}} \mathrm{CO}_{2}\right)$ ventilatory equivalents.

An individual is considered to reach $\mathrm{VO}_{2}$ max when, during maximal exercise, the progressive increase in the loads does not increase $\mathrm{VO}_{2}$ by more than $150 \mathrm{~mL} / \mathrm{min}$, and a plateau is graphically obtained ${ }^{5}$; when this plateau is not reached, the highest $\mathrm{VO}_{2}$ is called peak oxygen consumption $\left(\mathrm{VO}_{2} \text { peak }\right)^{1}$.

Although the cardiopulmonary exercise test is fundamental to the differential diagnosis of dyspnea, a small number of studies compares the metabolic and cardiorespiratory responses during exercise in patients with obstructive pulmonary diseases and congestive heart failure (CHF). This study aimed at differentiating the nature of functional limitation at maximal exercise in individuals with chronic obstructive pulmonary disease from that in individuals with congestive heart failure and at identifying indicators that may help in classifying these 2 clinical conditions by using the results obtained in cardiopulmonary exercise tests.

\section{Methods}

This study comprised 40 individuals divided into 2 groups. Group I comprised 23 individuals with COPD from the pulmonary rehabilitation program of the Center of Rehabilitation of UNIFESP/EPM - Lar Escola São Francisco. Of the 23 patients, 18 were males and 5 were females, with a mean age of 65.5 years ( 36 to 77). A 36-year-old patient had $\alpha 1$-antitripsin deficiency. On pulmonary function testing after bronchodilation, the following mean values were obtained: forced vital capacity (FVC) of $2.87 \pm 0.86 \mathrm{~L}(84 \pm 18.1 \%$ of the previewed); forced expiratory volume in 1 second $\left(\mathrm{FEV}_{1}\right)$ of $1.04 \pm$ $0.35 \mathrm{~L}(39.9 \pm 10.8 \%$ of the previewed theoretical value); and $\mathrm{FEV}_{1} / \mathrm{FVC}$ ratio of $37.5 \pm 9.2 \%$. Nine patients were classified as having moderate obstruction, and 14 patients as having severe obstruction ${ }^{6}$. The mean value of the partial pressure of oxygen $\left(\mathrm{PaO}_{2}\right)$ in the arterial blood was $68.3 \pm 6.7 \mathrm{~mm} \mathrm{Hg}$, of the partial pressure of carbon dioxide $\left(\mathrm{PaCO}_{2}\right)$ in the arterial blood was $37.8 \pm 4.5 \mathrm{~mm} \mathrm{Hg}$, and no patient had hypoxemia or hypercapnia. The patients were taking $\beta_{2}$-agonist, anticholinergic agents, oral or inhalant corticoid, or methylxanthine, or both, in optimized doses.

Group II comprised 17 individuals with CHF from the cardiomyopathy outpatient clinic of the discipline of cardiology of the UNIFESP/EPM, candidates for cardiac transplantation. Twelve were males and 5 females, with a mean age of 44.4 years (29 to 67) and a mean ejection fraction of $25.5 \pm$ $10.2 \%$. They were in NYHA functional class I to IV. In regard to the cause of the cardiomyopathy, of the 17 patients, 6 were classified as having ischemic heart disease, 6 as having chagasic heart disease, and 5 as having idiopathic heart disease. These patients with CHF underwent spirometry to eliminate ventilatory obstruction according to the requirements of the cardiac transplantation protocol. Two patients had cardiac pacemakers. The patients were taking an angiotensin-converting enzyme inhibitor, diuretics, digitalis, beta-blockers, amiodarone, or nitrate, or both, in optimized doses.

This study was submitted to and approved by the committee on ethics and research of the Universidade Federal de São Paulo/Escola Paulista de Medicina-Hospital São Paulo. The patients were informed about the study, and, after reading the information letter, they signed a formal written consent.

The 2 groups underwent maximal cardiopulmonary exercise testing on a treadmill (Lifestride-mod. 7500). The patient inhaled environmental air, and the expired air was analyzed with the Vista Mini CPX metabolic system (Vacumed, USA), which performed measurements of air volume, fractions of oxygen and carbon dioxide, and calculated the values of oxygen consumption, carbon dioxide production, and pulmonary ventilation, expressing the results every 30 seconds. All tests were monitored by the computerized ergometric system ERGO-S (Dixtal, São Paulo, Brazil). The peripheral saturation of oxygen $\left(\mathrm{SpO}_{2}\right)$ was determined with a Dixtal DX 2405 pulse oximeter(São Paulo, Brazil).

The Harbor protocol ${ }^{1}$ was used for the patients with pulmonary disease, with a constant velocity between 1.6 and $4 \mathrm{~km} / \mathrm{h}$ according to the patient's functional limitations, which were determined by previous tests. The protocol comprised a first stage of 3-minutes duration, with no incline, followed by stages of 1 -minute duration and $1 \%$ increases in incline. The protocol used for the patients with heart disease was proposed by Weber et $\mathrm{al}^{3}$ with a load increase every 2 minutes.

In all tests, the patient's exhaustion determined the interruption of the exertion phase.

Peak oxygen consumption was expressed in milliliters per kilo of weight per minute ( $\mathrm{mL} / \mathrm{kg} / \mathrm{min})$, in liters per minute $(\mathrm{L} / \mathrm{min})$, and as a percentage of maximal oxygen uptake previewed for sex and age. Peak oxygen consumption was calculated with the equations proposed by Barros Neto et $\mathrm{al}^{7}: \mathrm{VO}_{2} \mathrm{max}=52.727-0.3956 \mathrm{x}$ age (male sex) and $\mathrm{VO}_{2} \max =42.434-0.261 \mathrm{x}$ age (female sex). These equations were developed based on the results of tests performed in sedentary individuals.

Means and standard deviations of the variables were 
determined, and, to test the significance of the difference between the means of the 2 groups (individuals with pulmonary disease and individuals with heart disease) for each variable, the $t$ test for independent samples with equal variances was applied. Aiming at establishing a criterion of classification for patients, a differentiating analysis was performed according to Fisher's criterion, and multiple regression was applied to the ergospirometric variables to identify significant information for differentiating between the groups ${ }^{8}$.

\section{Results}

Body weight, height, and body mass index of the individuals with pulmonary disease were similar to those of the individuals with heart disease (tab. I).

Twenty individuals with pulmonary disease had oxyhemoglobin desaturation values on pulse oximetry below $90 \%$ during exertion (mean $\mathrm{SpO}_{2}$ at rest $=95 \pm 1.3 \%$; and mean $\mathrm{SpO}_{2}$ at peak exertion $=84.7 \pm 4.6 \%$ ); on the other hand, no patient with heart disease had $\mathrm{SpO}_{2}$ values below $90 \%$ on pulse oximetry (mean $\mathrm{SpO}_{2}$ at rest $=97.3 \pm 0.6 \%$; and mean $\mathrm{SpO}_{2}$ at peak exertion $=95.7 \pm 1.4 \%$ ).

The patients with COPD with oxyhemoglobin desaturation below $88 \%$ received oxygen supplementation during recovery. Although many patients had complex cardiac arrhythmias (mainly those with heart disease), administration of antiarrhythmic drugs was not required, because all arrhythmias ceased with exercise interruption.

The greatest oxygen consumption values $\left(\mathrm{VO}_{2}\right.$ peak $)$ reached during exercise were $17.5 \pm 3.2 \mathrm{~mL} / \mathrm{kg} / \mathrm{min}(66.9 \pm$ $13.3 \%$ of that previewed for sex and age) for the patients with pulmonary disease, and $19.3 \pm 3.7 \mathrm{~mL} / \mathrm{kg} / \mathrm{min}(57.6 \pm$ $12.7 \%$ of that previewed) for the patients with heart disease; no significant difference was observed between the groups. The 2 groups of patients had a $\mathrm{VO}_{2}$ peak value much lower than that previewed for sex and age, and the peak oxygen consumption values, expressed in $\mathrm{mL} / \mathrm{kg} / \mathrm{min}$ or $\mathrm{L} / \mathrm{min}$, were similar in the 2 groups (tab. II).

The anaerobic threshold could be determined by using the ventilatory method only in $6(26 \%)$ of the 23 patients with COPD; it could not be determined in the other patients, because they had an irregular ventilatory pattern. In the patients with CHF, the anaerobic threshold could be determined in all patients (tab. II). No difference was observed in peak heart rate (HR peak) and in peak oxygen pulse between the 2 groups (tab. II).

Although the peak pulmonary ventilation, peak current volume, and peak respiratory rate values in the patients with heart disease were higher than those in the patients with COPD, they were not pertinent for differentiating between the groups (tab. II).

The values of peak gas exchanges ( $\mathrm{R}$ peak), peak carbon dioxide production ( $\mathrm{VCO}_{2}$ peak), and peak oxygen ventilatory equivalent $\left(\mathrm{V}_{\mathrm{E}} \mathrm{O}_{2}\right.$ peak) were greater in patients with heart failure than in those with obstructive pulmonary disease, and these were the variables characterizing the differences between the groups (tab. III). For group classifi- cation, the differentiating functions with the $\mathrm{R}$ peak, $\mathrm{VCO}_{2}$ peak $(\mathrm{L} / \mathrm{min})$, and $\mathrm{V}_{\mathrm{E}} \mathrm{O}_{2}$ peak variables were used as follows: COPD group: $-44.886+78.832 \times \mathrm{Rpeak}+5.442 \times \mathrm{VCO}_{2}$ peak + $0.336 \mathrm{x} \mathrm{V}_{\mathrm{F}} \mathrm{O}_{2}$ peak; $\mathrm{CHF}$ group: $-69.251+89.740 \times \mathrm{R}$ peak + $8.461 \times \mathrm{VCO}_{2}$ peak $+0.574 \times \mathrm{V}_{\mathrm{E}} \mathrm{O}_{2}$ peak.

Applying the values of $\mathrm{R}$ peak, $\mathrm{VCO}_{2}$ peak, and $\mathrm{V}_{\mathrm{E}} \mathrm{O}_{2}$ peak to the 2 differentiating functions, the greatest result correctly classifies (in $90.0 \%$ of the cases) the group the patient belongs to.

The mean peak carbon dioxide ventilatory equivalent $\left(\mathrm{V}_{\mathrm{E}} \mathrm{CO}_{2}\right.$ peak) value, although higher in the patients with $\mathrm{CHF}$ than in those with COPD, was not important for differentiating between the groups (tab. III).

\section{Discussion}

Maximal oxygen uptake is the most important physiological measurement for defining cardiorespiratory functio-

\begin{tabular}{|lccc|}
\hline \multicolumn{4}{|c|}{$\begin{array}{c}\text { Table I - Weight, height, and body mass index (BMI) in patients with } \\
\text { pulmonary and heart diseases expressed as mean } \pm \text { standard deviation }\end{array}$} \\
\hline Variable & Pulmonary disease & Heart disease & $\mathrm{P}$ \\
\hline Weight $(\mathrm{kg})$ & $65.1 \pm 13.7$ & $64 \pm 15.2$ & 0.81 \\
Height $(\mathrm{cm})$ & $162.7 \pm 9$ & $163.7 \pm 10.9$ & 0.75 \\
BMI $\left(\mathrm{kg} / \mathrm{m}^{2}\right)$ & $24.4 \pm 4.3$ & $23.7 \pm 4.2$ & 0.58 \\
\hline
\end{tabular}

\begin{tabular}{|c|c|c|c|}
\hline \multicolumn{4}{|c|}{$\begin{array}{l}\text { Table II - Mean values and standard deviations of peak oxygen consump- } \\
\text { tion ( } \mathrm{VO}_{2} \text { peak), anaerobic threshold (AT), peak heart rate (HR peak), } \\
\text { peak oxygen pulse (peak } \mathrm{O}_{2} \text { pulse), peak pulmonary ventilation }\left(\mathrm{V}_{\mathrm{E}} \text { peak), }\right. \\
\text { peak current volume }\left(\mathrm{V}_{\mathrm{C}} \text { peak), and peak respiratory rate (f peak) of the }\right. \\
23 \text { patients with pulmonary disease and } 17 \text { patients with heart disease }\end{array}$} \\
\hline Variable & Pulmonary disease & Heart disease & $\mathrm{P}$ \\
\hline $\mathrm{VO}_{2}$ peak $(\mathrm{mL} / \mathrm{kg} / \mathrm{min})$ & $17.5 \pm 3.2$ & $19.3 \pm 3.7$ & 0.10 \\
\hline $\mathrm{VO}_{2}$ peak $(\mathrm{L} / \mathrm{min})$ & $1.16 \pm 0.39$ & $1.24 \pm 0.4$ & 0.54 \\
\hline $\mathrm{AT}^{2} *(\mathrm{~mL} / \mathrm{kg} / \mathrm{min})$ & $14.6 \pm 1.7$ & $13.8 \pm 3$ & 0.51 \\
\hline HR peak (bpm) & $133.2 \pm 16$ & $137.1 \pm 20.8$ & 0.51 \\
\hline Peak $\mathrm{O}_{2}$ pulse $(\mathrm{mL} /$ beat $)$ & $8.7 \pm 2.8$ & $9.1 \pm 3$ & 0.64 \\
\hline $\mathrm{V}_{\mathrm{E}}$ peak $(\mathrm{L} / \mathrm{min})$ & $37.3 \pm 12.3$ & $58.7 \pm 18.4$ & $<0.001$ \\
\hline $\mathrm{V}_{\mathrm{C}}$ peak $(\mathrm{L})$ & $1.12 \pm 0.33$ & $1.57 \pm 0.5$ & 0.002 \\
\hline f peak (breathings/min) & $34.3 \pm 6$ & $39.1 \pm 6.9$ & 0.02 \\
\hline
\end{tabular}

\begin{tabular}{|c|c|c|c|}
\hline \multicolumn{4}{|c|}{$\begin{array}{l}\text { Table III - Descriptive measures of the peak gas exchange ratio ( } \mathrm{R} \\
\text { peak), peak carbon dioxide production }\left(\mathrm{VCO} \mathrm{O}_{2} \text { peak), peak oxygen }\right. \\
\text { ventilatory equivalent }\left(\mathrm{V}_{\mathrm{E}} \mathrm{O}_{2} \text { peak), and peak carbon dioxide }\right. \\
\text { ventilatory equivalent }\left(\mathrm{V}_{\mathrm{E}} \mathrm{CO}_{2} \text { peak) of the } 23 \text { patients with pulmonary }\right. \\
\text { disease and } 17 \text { patients with heart disease }\end{array}$} \\
\hline Variable & Pulmonary disease & Heart disease & $P$ \\
\hline R peak * & $0.91 \pm 0.09$ & $1.08 \pm 0.11$ & $<0.001$ \\
\hline $\mathrm{VCO}_{2}$ peak $*(\mathrm{~L} / \mathrm{min})$ & $1.05 \pm 0.38$ & $1.31 \pm 0.41$ & 0.04 \\
\hline $\mathrm{V}_{\mathrm{E}} \mathrm{O}_{2}$ peak $*$ & $33.2 \pm 6.7$ & $50.4 \pm 11.4$ & $<0.001$ \\
\hline $\mathrm{V}_{\mathrm{E}} \mathrm{CO}_{2}$ peak & $37.2 \pm 7.6$ & $46.2 \pm 9.9$ & 0.002 \\
\hline
\end{tabular}


nal capacity. The direct collection of the expired gases during exercise is necessary for clinical or investigative situations, such as congestive heart failure and sports training, for the direct determination of $\mathrm{VO}_{2} \max$ and anaerobic threshold ${ }^{9}$. In patients with COPD, the variables obtained on cardiopulmonary tests are also the best indicators of aerobic potency ${ }^{6}$, and, as already indicated, those tests are fundamental for the differential diagnosis of the cause of dyspnea.

All tests performed in this study were maximal, because the tests interrupted due to clinical criteria before the patient reached exhaustion were excluded from the sample. However, we preferred to adopt the nomenclature of peak oxygen consumption instead of maximal oxygen uptake, because the $\mathrm{VO}_{2}$ plateau was not always reached.

The group of patients with obstructive pulmonary disease had a mean age greater than that of patients with heart disease. This occurred because the incidence of chronic obstructive pulmonary disease markedly increases with age $^{6}$; on the other hand, the patients with heart disease were younger, because the younger were given priority for cardiac transplantation. Maximal oxygen uptake decreases as age increases after 25 years of age ${ }^{10}$. However, $\mathrm{VO}_{2}$ peak measured was much lower that that previewed for sex and age in the 2 groups, and the values of $\mathrm{VO}_{2}$ peak measured were very similar in the 2 groups. We believe that, despite the age difference between the groups, the cardiorespiratory limitation to exercise was caused by the disease in both groups.

The cause of cardiomyopathy in the patients with CHF varied. However, Yazbek Jr et a ${ }^{11}$ compared the modifications in the variables obtained with the cardiopulmonary exercise test in groups of patients with ischemic cardiomyopathy, idiopathic cardiomyopathy, or cardiomyopathy due to Chagas' disease. Those authors found no significant difference in the 3 groups. Therefore, the fact that we studied patients with cardiomyopathies of different causes may not have influenced our results.

We recognize that the lack of a healthy control group, the reduced number of patients studied in both groups, and the use of a different protocol for each group are limitations of this study that may have influenced the results.

However, the results of $\mathrm{VO}_{2}$ peak obtained in this study are similar to those reported in the literature both for patients with pulmonary disease ${ }^{2,12,13}$ and patients with heart disease ${ }^{14-17}$.

As expected, most patients with COPD (87\%) had oxyhemoglobin desaturation below $90 \%$ during exercise, which suggests worsening of gas exchange during maximum exertion in that group of patients ${ }^{3}$. No patient with CHF had oxyhemoglobin desaturation below $90 \%$ during exercise.

The anaerobic threshold was determined by using the ventilatory method in only $26 \%$ of the patients with COPD, which was expected, because the impossibility of determining this index is considered one of the criteria of ventilatory limitation ${ }^{3,4}$. On the other hand, the fact that the ventilatory anaerobic threshold was determined in all patients with heart disease was also expected, because that index was initially described in patients with heart disease ${ }^{18}$, and, like $\mathrm{VO}_{2} \max$, was used to classify patients functionally ${ }^{3}$.

The values of peak heart rate and peak oxygen pulse were similar in both groups; therefore, these variables are not important for differentiating between patients with COPD and CHF. Although the mean values of peak ventilation, peak current volume, and peak respiratory rate were greater in patients with heart disease than in patients with pulmonary disease, the differences were not important for classifying the patients into the groups.

The peak values of carbon dioxide production, of gas exchange ratio, and of oxygen ventilatory equivalent were greater in patients with heart disease than those in patients with pulmonary disease, allowing characterization of the differences between the groups and the use of the differentiating functions to classify the patients in each group. The peak values of carbon dioxide ventilatory equivalent, although greater in patients with heart disease as compared with those in patients with pulmonary disease, were not important for classifying those patients.

These results seem to agree with those reported in the literature, because $\mathrm{V}_{\mathrm{E}} \mathrm{O}_{2}$ usually decreases to its lowest values in the anaerobic threshold, and then begins to increase, and $\mathrm{V}_{\mathrm{E}} \mathrm{CO}_{2}$ decreases to its lowest values in the point of respiratory compensation, which is triggered in response to metabolic acidosis, and then begins to increase continuously ${ }^{1}$.

Patients with obstructive pulmonary disease usually have an altered ventilation/perfusion ratio, and, therefore, their $\mathrm{V}_{\mathrm{E}} \mathrm{CO}_{2}$ is high. However, due to their impaired respiratory mechanics, their ventilation is limited and those patients do not usually hyperventilate in response to metabolic acidosis. That is why, despite metabolic acidosis, $\mathrm{V}_{\mathrm{E}} \mathrm{CO}_{2}$ does not increase in tests with increasing loads. The normal response of $\mathrm{V}_{\mathrm{E}} \mathrm{O}_{2}$ is to increase the load above the anaerobic threshold, and this increase depends on the magnitude of lactic acidosis and sensitivity of the chemoreceptors to acidosis. $\mathrm{V}_{\mathrm{E}} \mathrm{O}_{2}$ does not increase above the anaerobic threshold if the chemoreceptors for detecting the increase in $\mathrm{H}^{+}$are not sensitive. Patients with COPD may not reach their lower $\mathrm{V}_{\mathrm{E}} \mathrm{O}_{2}$ levels during maximal exercise ${ }^{1}$, because of the sensitivity of the chemoreceptors.

On the other hand, patients with heart failure have an exaggerated ventilatory response in regard to energy needs ${ }^{1}$.

According to our understanding, the low $\mathrm{VCO}_{2}$ peak and $\mathrm{R}$ peak values may be explained by the same factors implicit in the explanation of the low $\mathrm{V}_{\mathrm{E}} \mathrm{O}_{2}$ peak and $\mathrm{V}_{\mathrm{E}} \mathrm{CO}_{2}$ peak values found in the tests of patients with COPD. These patients do not manage to increase their carbon dioxide removal because pulmonary ventilation does not effectively increase, and the gas exchange ratio does not also increase as expected. It is important to stress that $\mathrm{R}$ peak values lower than 1 indicate that the $\mathrm{V}_{\mathrm{E}} \mathrm{CO}_{2}$ peak value is necessarily greater than $\mathrm{V}_{\mathrm{E}} \mathrm{O}_{2}$ peak, and that the patient is not eliminating carbon dioxide as expected.

It is worth noting that the $\mathrm{R}$ peak value in tests of patients with COPD and CHF is not valued much by most 
authors. Although this variable is extremely altered with voluntary respiratory maneuvers, the results of other studies have also suggested that $R$ peak values are lower in patients with COPD with a greater obstruction on cardiopulmonary exercise testing ${ }^{19,20}$. We emphasize that our sample comprised patients with pulmonary disease with moderate to severe obstruction on cardiopulmonary exercise testing, ie, patients expected to have lower $\mathrm{R}$ values (and, therefore, lower ventilation) on maximal exercise.

On the other hand, patients with heart disease have no difficulty in eliminating carbon dioxide, and $\mathrm{R}$ peak values greater than 1 are expected in their tests ${ }^{21-23}$.

Because of these considerations, we believe that our results of $\mathrm{R}$ peak and $\mathrm{VCO}_{2}$ peak obtained in patients with obstructive pulmonary disease and heart failure were as expected.
The $\mathrm{V}_{\mathrm{E}} \mathrm{CO}_{2}$ peak values were greater in patients with heart disease as compared with those in patients with pulmonary disease, but were not important in the classification of these patients perhaps due to the reduced number of patients studied and the use of different protocols for each group of patients.

We also believe that the differentiating functions should not be randomly used to identify the cause of functional limitations in patients with COPD and CHF, because of the limitations of this study already cited.

In conclusion, $\mathrm{R}$ peak, $\mathrm{VCO}_{2}$ peak, and $\mathrm{V}_{\mathrm{E}} \mathrm{O}_{2}$ peak values may be used as auxiliary tools in the differential diagnosis of the cause of the cardiorespiratory functional limitations of patients with COPD and CHF. The numeric results of these variables, applied to their respective differentiating functions, may be useful for classifying patients with COPD or CHF.

\section{References}

1. Wasserman K, Hansen JE, Sue DY, Casaburi R, Whipp BJ. Principles of Exercise Testing and Interpretation. Lippincott Williams \& Wilkins, $3^{\text {st }}$ ed.1999: 556 pp.

2. Nery LE, Wasserman K, French W, Oren A, Davis JA. Contrasting cardiovascular and respiratory responses to exercise in mitral valve and chronic obstructive pulmonary diseases. Chest 1983; 83:446-53.

3. Weber KT, Janicki JS, McElroy PA, Reddy HK. Concepts and applications of cardiopulmonary exercise testing. Chest 1988; 93:843-7.

4. Babb TG. Mechanical ventilatory constraints in aging, lung disease, and obesity: perspectves and brief review. Med. Sci. Sports Exerc 1991; Suppl.:S12-S22.

5. Taylor, Hl, Buskirk E, Henschel A. Maximal oxygen intake as an objective measure of cardiorespiratory performance. J Appl Physiol 1955; 8:73-80.

6. I Consenso Brasileiro de Doença Pulmonar Obstrutiva Crônica (DPOC). J Pneumol 2000; 26(Supl 1):S1-S52.

7. Barros Neto TL, Cesar MC, Tambeiro VL. Avaliação da aptidão física cardiorrespiratória. In: Ghorayeb N e Barros T, eds. O Exercício: Preparação Fisiológica, Avaliação Médica, Aspectos Especiais e Preventivos. Atheneu, 1999; 15-24.

8. Johnson RA, Wichern DW. Applied Multivariate Statistical Analyses. 1998; 629-723.

9. Consenso Nacional de Ergometria. Arq Bras Cardiol 1995; 65:189-211.

10. American College of Sports Medicine. Position on exercise and physical activity for older adults. Med Sci Sports Exerc 1998; 30:992-1008.

11. Yazbek Jr P, Diament J, Haebisch H, et al. Ergoespirometria como método de predição do comportamento evolutivo da miocardiopatia isquêmica, chagásica e idiopática. Arq Bras Cardiol 1991; 57:451-8.

12. Punzal PA, Ries AL, Kaplan RM, Prewitt, LM. Maximum intensity exercise training in patients with chronic obstructive pulmonary disease. Chest 1991; 100:618-23.

13. Mador MJ, Kufel TJ. Reproducibility of visual analog scale measurements of dyspnea in patients with chronic obstructive pulmonary disease. Am Rev Respir Dis 1992; 146:82-7.
14. Riley M, Stanford CF, Nicholls DP. Ventilatory and heart rate responses after exercise in chronic cardiac failure. Clin Sci 1994; 87:231-8.

15. Cohen-Solal A, Laperche T, Morvan D, Geneves M, Caviezel B, Gourgon R. Prolonged kinetics of recovery of oxygen consumption after maximal graded exercise in patients with chronic heart failure: analysis with gas exchange measurements and NMR spectroscopy. Circulation 1995; 91:2924-32.

16. Daida H, Allison TG, Johnson BD, Squires RW, Gau GT. Further increase in oxygen uptake during early active recovery following maximal exercise in chronic heart failure. Chest 1996; 109:47-51.

17. Brunner La Rocca HPB, Weilenmann D, et al. Oxygen uptake kinects during low level exercise in patients with heart failure: relation to neurohomones, peak oxygen consumption, and clinical findings. Heart 1999; 81:121-7.

18. Wasserman K, Mc Ilroy MB. Detecting the threshold of anaerobic metabolism in cardiac patients during exercise. Am J Cardiol 1964; 14:844-52.

19. LoRusso TJ, Belman MJ, ElashoffJD, Koerner SK. Predictor of maximal exercise capacity in obstructive and restrictive pulmonary disease. Chest 1993; 104: 1748-54.

20. Carter R, Nicotra B, Huber G. Differing effects of airway obstruction on physical work capacity and ventilation in men and women with COPD. Chest 1994; 106:1730-9.

21. Weber KT, Kinasewitz GT, Janicki JS, Fishman AP. Oxygen utilization and ventilation during exercise in patients with chronic cardiac failure. Circulation 1982; 65:1213-23.

22. Mady C, Yazbek Jr P, Barretto ACP, et al. Estudo da capacidade funcional máxima pela ergoespirometria em pacientes portadores da doença de Chagas. Arq Bras Cardiol 1986; 47:201-5.

23. Cohen-Solal A, Czitrom D, Geneves M., Gourgon R. Delayed attainment of peak oxygen consumption after the end of exercise in patients with chronic heart failure. Int J Cardiol 1997;60:23-9. 